\title{
Pengukuran Kepuasan Mahasiswa Terhadap Pelayanan Prodi di Fakultas Ilmu Komputer Universitas Lancang Kuning
}

\author{
Ahmad Zamsuri ${ }^{1}$, Sutejo ${ }^{2}$, Lisnawita ${ }^{3}$ \\ ${ }^{1,2,3}$ Program Studi Teknik Informatika Fakultas Ilmu Komputer, Universitas Lancang Kuning \\ Jln. Yos Sudarso Km 8 Pekanbaru, Telp. (+628117532015) \\ Email: ${ }^{1}$ ahmadzamsuri@unilak.ac.id, ${ }^{2}$ sutejo@dr.com, ${ }^{3}$ lisnawita@unilak.ac.id
}

\begin{abstract}
Abstrak
Penelitian ini bertujuan untuk mengetahui: pengaruh bukti fisik terhadap kepuasan mahasiswa, pengaruh keandalan terhadap kepuasan mahasiswa, pengaruh daya tanggap terhadap kepuasan mahasiswa, pengaruh jaminan terhadap kepuasan mahasiswa, pengaruh empati terhadap kepuasan mahasiswa, interaksi pengaruh bukti fisik, keandalan, daya tanggap, jaminan, dan empati terhadap kepuasan mahasiswa. Penelitian ini merupakan penelitian kuantitatif dengan pendekatan survey. Sampel yang digunakan adalah 151 responden dari 243 responden siswa, ditentukan oleh rumus Yamane (1967), sedangkan teknik pengambilan sampel menggunakan metode Simple Random Sampling. Uji instrumen pemeriksaan dengan menggunakan uji validitas, uji reliabilitas dan uji asumsi klasik. Teknik analisis data menggunakan regresi linier berganda dengan uji hipotesis (uji $F$ dan uji t). Hasil penelitian menunjukkan bahwa dari hasil uji F-test, lima dimensi kualitas yang sama untuk kepuasan mahasiswa di Fakultas Ilmu Komputer (Y). Dari hasil perhitungan t-test terbukti bahwa variabel reliability (X1), responsiveness (X2), asuransi (X3) dan tangible assets (X5) berpengaruh signifikan terhadap variabel dependen (Y), sedangkan variabilitas empati (X4) tidak berpengaruh signifikan terhadap variabel dependen Y). Dari hasil perhitungan koefisien determinasi (Adjusted $R$ Square) menghasilkan nilai 0,145, yang berarti bahwa pengaruh variabel bebas terhadap variabel terikat adalah 14,5\%, sedangkan sisanya 85,5\% dari variabel lain dipengaruhi di luar lima variabel bebas.
\end{abstract}

Kata kunci: Kualitas pelayanan, kepuasan mahasiswa, pendidikan

\begin{abstract}
This study aims to determine:the influence of physical evidence on student satisfaction, the influence of reliability on student satisfaction, the influence of responsiveness to student satisfaction, influence of guarantee to student satisfaction, student satisfaction, interaction of influence of physical evidence, reliability, responsiveness, assurance, and empathy toward student satisfaction. This research is a quantitative research with survey approach. The sample used was 151 respondents from 243 respondents students, determined by the formula Yamane (1967), while the sampling technique using Simple Random Sampling method. Test the examination instrument using validity test, reliability test and classical assumption test. Data analysis technique using multiple linear regression with hypothesis test ( $F$ test and $t$ test). The results showed that from the F-test results, the same five dimensions of quality for student satisfaction at the Faculty of Computer Science (Y). From t-test result, it is proved that the variable of reliability $(X 1)$, responsiveness $(X 2)$, insurance $(X 3)$ and tangible assets $(X 5)$ have significant effect on dependent variable $(Y)$, while empathy variation $(X 4)$ has no significant effect on the dependent variable $Y$ ). From result of calculation of coefficient of determination (Adjusted $R$ Square) yield value 0,145, which means that influence of independent variable to dependent variable is $14,5 \%$, while the rest $85,5 \%$ from other variable influenced outside five independent variable.
\end{abstract}

Keywords: Quality of service, student satisfaction, education 


\section{Pendahuluan}

Arambewela dan Hall (2009) mengemukakan, "A satisfied student population is a source of competitive advantage with outcomes such as positive word of mouth (WOM) communication, student retention and loyalty" (hlm. 555). Artinya, mahasiswa yang puas dapat menjadi sumber keunggulan bersaing yang akan menghasilkan komunikasi dalam bentuk possitive word of mouth, retensi dan loyalitas mahasiswa. Kepuasan pelanggan menurut Jasfar (2005), "Perbandingan antara persepsinya terhadap jasa yang diterima dengan harapannya sebelum menggunakan jasa tersebut" (hlm. 49).

Goetsch Davis (1994) mengungkapkan bahwa kualitas merupakan suatu kondisi dinamis yang berhubungan dengan produk, jasa, manusia, proses, dan lingkungan yang memenuhi atau melebihi harapan (Yamit, 2005). Kualitas layanan mencerminkan perbandingan antara tingkat layanan yang disampaikan oleh perusahaan dibandingkan dengan ekspektasi pelanggan. Kualitas

layanan diwujudkan melalui pemenuhan kebutuhan dan keinginan pelanggan serta ketepatan penyampaiannya dalam mengimbangi atau melampaui harapan pelanggan (Tjiptono, Chandra, dan Adriana, 2008)

Pelayanan akademik adalah suatu kegiatan akademik yang ditawarkan kepada suatu pihak (mahasiswa) baik secara langsung maupun tidak langsung dalam rangka pencapaian tujuan akademik. Kepuasan mahasiswa ditentukan oleh kualitas layanan yang berkaitan dengan akademik. Menurut Tampubolon (2001), layanan akademik memiliki porsi yang sangat besar dalam layanan pendidikan. Oleh sebab itu, layanan akademik merupakan layanan yang banyak berkaitan secara langsung dengan mahasiswa. Universitas dapat meningkatkan kepuasan mahasiswa dengan cara menjalankan pelayanan akademik yang berkualitas yaitu dapat memenuhi kebutuhan dan keinginan mahasiswa. Pelayanan akademik yang berkualitas memberikan dorongan bagi mahasiswa untuk menjalin ikatan yang saling menguntungkan dalam jangka panjang. Mahasiswa yang puas akan memberikan manfaat bagi institusi, misalnya mereka akan terus menggunakan jasa institusi tersebut dengan studi lanjut, mereka juga dapat mempromosikan kepada orang lain sehingga pada akhirnya akan meningkatkan citra dari institusi tersebut.

Fakultas Ilmu Komputer Universitas Lancang Kuning, sebagai salah satu institusi pendidikan yang memiliki komitmen untuk menghasilkan pendidikan yang bermutu, dapat melakukan pengukuran tingkat kepuasan pelanggannya. Hal ini untuk menentukan apakah Fakultas Ilmu Komputer Universitas Lancang Kuning telah mampu memenuhi ketentuanketentuan yang diharapkan oleh pelanggannya.

Penelitian Terkait yang pernah dilakukan Van FC, Lucky Lhaura L, Lisnawita(2017) dengan adanya analisis kepuasan pelayanan pada CV. FAMILY, maka pada CV. FAMILY pelayanan yang diberikan termasuk kategori puas, dengan dipengaruhi oleh pelayanan dan harga serta pelayanan jasa yang telah diberikan

\section{Kepuasan Pelayanan}

Kepuasan merupakan tingkat perasaan seseorang setelah membandingkan kinerja (atau hasil) yang dirasakan dibandingkan dengan harapannya. Jadi tingkat kepuasan adalah fungsi dari perbedaan antara kinerja yang dirasakan dengan harapan. Kepuasan pelanggan merupakan evaluasi purna beli dimana alternatif yang dipilih sekurang-kurangnya sama atau melampaui harapan pelanggan, sedangkan ketidakpuasan timbul apabila hasil (outcome) tidak memenuhi harapan( Annisa Febriani, 2012).

\section{Pelayanan}

Kualitas pelayanan yang baik dimana perusahaan mampu memberikan pelayanan yang memuaskan agar terpenuhinya permintaan dan harapan konsumen (Sugiarto, 2000). Pelayanan 
adalah suatu kegiatan atau urutan kegiatan yang terjadi dalam interaksi langsung antara seseorang dengan orang lain atau mesin secara fisik dan menyediakan kepuasaan pelanggan. Dalam Kamus Besar Bahasa Indonesia dijelaskan pelayanan sebagai usaha melayani kebutuhan orang lain.

\section{Kepuasan Mahasiswa}

Menurut Iswani, Yanti (2011), kepuasan mahasiswa adalah suatu keadaan dimana terpenuhinya keinginan, harapan, dan kebutuhan mahasiswa. Jika pelayanan yang diberikan dapat memenuhi keinginan, harapan, dan kebutuhan mahasiswa, maka dapat dinilai pelayanan itu memuaskan, dan sebaliknya, jika pelayanan yang diberikan tidak dapat memenuhi keinginan, harapan, dan kebutuhan mahasiswa, maka dapat disimpulkan pelayanan itu tidak memuaskan. Maka berdasarkan definisi tersebut, dapat disimpulkan bahwa kepuasan mahasiswa merupakan penilaian yang diberikan atas perbedaan antara harapan mahasiswa dengan kinerja atau hasil (kenyataan) yang dirasakan oleh mahasiswa atas pelayanan yang diberikan olehfakultas.

\section{Teori Kepuasan Dan Ketidakpuasan}

Pada dasarnya pelanggan berhak menilai suatu perusahaan atau instansi dalam mengeluarkan output baik jasa dalam memenuhi harapan pelanggan atau sebaliknya membuat pelanggan merasa kesal. Harapan pelanggan yang terpenuhi akan membawa pada kondisi emosional pelanggan kearah kepuasan, dan sebaliknya bila harapan pelanggan tidak terpenuhi pelanggan akan merasa tidak puas sehingga bisa melakukan voice action (Kritikan atau keluhan).

Sunarto (2003) menyatakan bahwa untuk memahami dan mempengaruhi kepuasan atau ketidakpuasan menggunakan model diskonfirmasi Ekspektasi. Teori Diskonfirmasi Ekspektasi mendefinisikan kepuasan dan ketidakpuasan sebagai evaluasi yang dilakukan pelanggan sebagai pengalaman yang setidaknya sama baiknya dengan apa yang diharapkan.

\section{Metode penelitian Desain Riset}

Desain riset yang digunakan adalah desain asosiatif kausal. Hubungan kausal merupakan bentuk hubungan yang sifatnya sebab-akibat, artinya keadaan satu variabel disebabkan atau ditentukan oleh keadaan satu atau lebih variabel lain. Dalam penelitian ini, yang akan dianalisis adalah pengaruh kualitas pelayanan yang terdiri dari keandalan (reliability), daya tanggap (responsiveness), kepastian (assurance), ketulusan (empathy), dan bukti fisik (tangibles) terhadap kepuasan mahasiswa (bukankah ini model/metode servqual?)-sebaiknya servqualnya disebutkan dalam judul, dimana kualitas pelayanan merupakan variabel yang mempengaruhi (independen), sedangkan kepuasan mahasiswa merupakan variabel yang dipengaruhi (dependen).

\section{Jenis dan Sumber Data}

Data yang digunakan adalah data primer yang diperoleh melalui penyebaran kuesioner (angket) kepada responden yang telah sesuai dengan kriteria yang telah ditetapkan yaitu tentang penilaian atau persepsi mahasiswa terhadap kualitas pelayanan Fakultas Ilmu Komputer Universitas Lancang Kuning dan dampaknya terhadap kepuasan mahasiswa. Pendekatan yang digunakan dalam penelitian ini adalah pendekatan survei.

\section{Populasi}

Populasi dalam penelitian ini adalah seluruh mahasiswa Fakultas Ilmu Komputer yang terdaftar sebagai mahasiswa aktif untuk tahun ajaran 2016/2017. Mahasiswa di Fakultas Ilmu Komputer adalah keseluruhan mahasiswa dari 2 (dua) program studi yaitu Program studi Teknik 
Informatika dan Program Studi Sistem informasi. Populasi berjumlah 243 yang terdiri dari mahasiswa laki-laki dan perempuan. Data populasi penelitian dapat dilihat pada tabel berikut :

Tabel 1 Populasi Penelitian

\begin{tabular}{|l|l|l|l|l|}
\hline Program Studi & Angkatan & Laki-Laki & Perempuan & Jumlah Mahasiswa \\
\hline Sistem Informatika & 2014 & 38 & 31 & 69 \\
\hline Teknik Informatika & 2014 & 132 & 42 & 174 \\
\hline Total Mahasiswa & 170 & 73 & 243 \\
\hline
\end{tabular}

\section{Sampel}

Teknik penarikan sampel dilakukan dengan Metode Sampel Acak Sederhana (Simple Random Sampling Method). Penentuan ukuran sampel penelitian dilakukan dengan menggunakan rumus Yamane (1967: 886) dalam Sarwono \& Suhayati (2010):

$$
n=\frac{N}{1+N(e)^{2}}=\frac{243}{1+243(0,05)^{2}}=151,21 \text { responden }
$$

Keterangan:

$\mathrm{n}=$ Jumlah sampel

$\mathrm{N}=$ Jumlah Populasi

$\mathrm{e}=$ Tingkat presisi (sampling error) yaitu sebesar 7\%

\section{Hasil dan pembahasan}

Tabel 2 Karakteristik responden berdasarkan jenis kelamin

\begin{tabular}{|l|l|l|}
\hline Jenis Kelamin & $\begin{array}{l}\text { Frekuensi } \\
(\text { Orang })\end{array}$ & $\begin{array}{l}\text { Persentase } \\
(\boldsymbol{\%})\end{array}$ \\
\hline Laki-Laki & 55 & 36 \\
\hline Perempuan & 96 & 64 \\
\hline Total & $\mathbf{1 5 1}$ & $\mathbf{1 0 0}$ \\
\hline
\end{tabular}

Responden ternyata didominasi oleh mahasiswa yang berjenis kelamin perempuan sebanyak 96 orang dengan persentase $64 \%$ dan sisanya adalah responden laki-laki sebanyak 55 orang atau $36 \%$. Hal ini sesuai dengan kenyataan jumlah populasi mahasiswa Fakultas Ilmu Komputer Universitas Lancang Kuning yang sesungguhnya memang didominasi oleh kaum perempuan.

Tabel 3 Karakteristik responden berdasarkan jurusan

\begin{tabular}{|l|l|l|}
\hline Tahun Angkatan & $\begin{array}{l}\text { Frekuensi } \\
\text { (Orang) }\end{array}$ & $\begin{array}{l}\text { Persentase } \\
(\mathbf{\%})\end{array}$ \\
\hline Sistem Informasi & 70 & 46 \\
\hline Teknik Informatika & 81 & 54 \\
\hline Total & $\mathbf{1 5 1}$ & $\mathbf{1 0 0}$ \\
\hline
\end{tabular}

Responden ternyata didominasi oleh mahasiswa jurusan teknik informatika sebanyak 81 orang dengan persentase 54\% dan sisanya adalah mahasiswa jurusan sistem informasi sebanyak 
70 orang atau $46 \%$. Jurusan responden menunjukkan pengalaman atau telah banyaknya responden menerima dan merasakan pelayanan yang diberikan oleh prodi fakultas, sehingga akan berpengaruh pada kemampuan analitisnya dalam pengisian kuesionerini.

Tabel 4 Karakteristik responden berdasarkan usia

\begin{tabular}{|l|l|l|}
\hline Usia (Tahun) & Frekuensi (Orang) & Persentase (\%) \\
\hline $19-24$ & 138 & 91 \\
\hline $25-30$ & 13 & 9 \\
\hline Total & $\mathbf{1 5 1}$ & $\mathbf{1 0 0}$ \\
\hline
\end{tabular}

Responden didominasi oleh mahasiswa berusia muda, yakni 19-24 tahun sebanyak 81 orang dengan persentase $91 \%$ dan sisanya mahasiswa berusia 25-30 tahun sebanyak 13 orang atau hanya $9 \%$.

Tabel 5 Karakteristik responden berdasarkan pernah tidaknya mengurus beasiswa

\begin{tabular}{|l|l|l|}
\hline Pernah / Tidak & $\begin{array}{l}\text { Frekuensi } \\
(\text { Orang) }\end{array}$ & $\begin{array}{l}\text { Persentase } \\
(\mathbf{\%})\end{array}$ \\
\hline Pernah & 116 & 77 \\
\hline Tidak Pernah & 35 & 23 \\
\hline Total & $\mathbf{1 5 1}$ & $\mathbf{1 0 0}$ \\
\hline
\end{tabular}

Responden didominasi oleh mahasiswa yang pernah mengurus beasiswa, yakni sebanyak 116 orang dengan persentase $77 \%$ dan sisanya adalah mahasiswa yang tidak pernah mengurus beasiswa sebanyak 35 orang dengan persentase $23 \%$. Hal ini penting diketahui, mengingat pengaruhnya terhadap persepsi mahasiswa terhadap pelayanan yang diberikan oleh fakultas, terutama yang berkaitan dengan pegawai atau staf administrasi.

Tabel 6 Karakteristik responden berdasarkan sudah belumnya melaksanakan PKL(Praktek Kerja Lapangan)/ Field Trip

\begin{tabular}{|l|l|l|}
\hline Sudah / Belum & $\begin{array}{l}\text { Frekuensi } \\
\text { (Orang) }\end{array}$ & $\begin{array}{l}\text { Persentase } \\
(\mathbf{\%})\end{array}$ \\
\hline Sudah & 69 & 46 \\
\hline Belum & 82 & 54 \\
\hline Total & $\mathbf{1 5 1}$ & $\mathbf{1 0 0}$ \\
\hline
\end{tabular}

Responden didominasi oleh mahasiswa yang belum melaksanakan PKL (Praktek Kerja Industri) / Field Trip sebanyak 82 orang (54\%) dan sisanya mahasiswa yang sudah melaksanakan PKL (Praktek Kerja Industri) / Field Trip sebanyak 69 orang (46\%). 
Tabel 7 Distribusi frekuensi item variabel Keandalan (Reliability)

\begin{tabular}{|c|c|c|c|c|c|c|c|c|c|c|c|}
\hline \multirow[t]{2}{*}{ Variabel } & \multicolumn{2}{|c|}{$\begin{array}{l}1 \\
\text { STB }\end{array}$} & \multicolumn{2}{|l|}{$\begin{array}{l}2 \\
\text { TB }\end{array}$} & \multicolumn{2}{|l|}{$\begin{array}{l}3 \\
\text { CB }\end{array}$} & \multicolumn{2}{|l|}{$\begin{array}{l}4 \\
\text { B }\end{array}$} & \multicolumn{2}{|c|}{$\begin{array}{l}5 \\
\text { SB }\end{array}$} & \multirow{2}{*}{$\begin{array}{l}\text { Statistik } \\
\text { Mean }\end{array}$} \\
\hline & $\mathbf{F}$ & $\%$ & $\mathbf{F}$ & $\%$ & $\mathbf{F}$ & $\%$ & $\mathbf{f}$ & $\%$ & $\mathbf{f}$ & $\%$ & \\
\hline $\mathrm{X} 1.1$ & - & - & 4 & 2,65 & 89 & 58,94 & 58 & 38,41 & - & - & 3,36 \\
\hline $\mathrm{X} 1.2$ & 7 & 4,64 & 34 & 22,52 & 62 & 41,06 & 48 & 31,79 & - & - & 3 \\
\hline $\mathrm{X} 1.3$ & - & - & 45 & 29,8 & 66 & 43,71 & 40 & 26,49 & - & - & 2,97 \\
\hline $\mathrm{X} 1.4$ & - & - & 8 & 5,29 & 56 & 37,09 & 87 & 57,62 & - & - & 3,52 \\
\hline $\mathrm{X} 1.5$ & 20 & 13,25 & 48 & 31,79 & 83 & 54,97 & - & - & - & - & 2,42 \\
\hline $\mathrm{X} 1.6$ & 14 & 9,27 & 56 & 37,09 & 81 & 53,64 & - & - & - & - & 2,44 \\
\hline X1.7 & - & - & 20 & 13,25 & 90 & 59,6 & 41 & 27,15 & - & - & 3,11 \\
\hline $\mathrm{X} 1.8$ & - & - & 52 & 34,44 & 69 & 45,7 & 30 & 19,87 & - & - & 2,85 \\
\hline
\end{tabular}

Dari delapan item pernyataan variabel keandalan (reliability), distribusi rata-rata tertinggi jawaban responden terletak pada item dosen menguasai pemakaian alat bantu yang dipakai selama proses perkuliahan (X1.4) dengan rata-rata 3,52. Hal ini menunjukkan bahwa dosen benar-benar menguasai pemakaian alat bantu yang dipakai selama proses perkuliahan berlangsung. Sedangkan distribusi rata-rata terendah jawaban responden terletak pada item ketepatan dan kecepatan pelayanan administrasi oleh pegawai/ staf (profesionalisme staf) (X1.5) dengan rata-rata 2,42. Hal ini menunjukkan bahwa pegawai/ staf di bagian administrasi masih kurang tepat waktu dalam menyelesaikan permasalahan administratif mahasiswa Fakultas Ilmu Komputer.

Tabel 8 Distribusi frekuensi item variabel daya tanggap (Responsiveness)

\begin{tabular}{|c|c|c|c|c|c|c|c|c|c|c|c|}
\hline \multirow[t]{2}{*}{ Variabel } & \multicolumn{2}{|c|}{\begin{tabular}{|l}
1 \\
STB \\
\end{tabular}} & \multicolumn{2}{|c|}{$\begin{array}{l}2 \\
\text { TB } \\
\end{array}$} & \multicolumn{2}{|c|}{$\begin{array}{l}3 \\
\mathrm{CB}\end{array}$} & \multicolumn{2}{|l|}{$\begin{array}{l}4 \\
\text { B }\end{array}$} & \multicolumn{2}{|c|}{$\begin{array}{l}5 \\
\text { SB }\end{array}$} & \multirow{2}{*}{$\begin{array}{l}\text { Statistik } \\
\text { Mean }\end{array}$} \\
\hline & f & $\%$ & $\mathbf{F}$ & $\%$ & $\mathbf{F}$ & $\%$ & f & $\%$ & $\mathbf{f}$ & $\%$ & \\
\hline $\mathrm{X} 2.1$ & 16 & 10,6 & 76 & 50,33 & 59 & 39,07 & - & - & - & - & 2,28 \\
\hline $\mathrm{X} 2.2$ & - & - & 17 & 11,26 & 96 & 63,58 & 38 & 25,17 & - & - & 3,14 \\
\hline $\mathrm{X} 2.3$ & - & - & 21 & 13,91 & 93 & 61,59 & 37 & 24,5 & - & - & 3,11 \\
\hline X2.4 & - & - & 11 & 7,28 & 81 & 53,64 & 59 & 39,07 & - & - & 3,32 \\
\hline $\mathrm{X} 2.5$ & - & - & 59 & 39,07 & 62 & 41,06 & 30 & 19,87 & - & - & 2,81 \\
\hline $\mathrm{X} 2.6$ & 21 & 13,91 & 61 & 40,4 & 50 & 33,11 & 19 & 12,58 & - & - & 2,44 \\
\hline $\mathrm{X} 2.7$ & - & - & 25 & 16,56 & 86 & 56,95 & 40 & 26,49 & - & - & 3,1 \\
\hline $\mathrm{X} 2.8$ & - & - & 54 & 35,76 & 62 & 41,06 & 35 & 23,18 & - & - & 2,87 \\
\hline
\end{tabular}


Dari delapan item pernyataan variabel daya tanggap (responsiveness), distribusi rata-rata tertinggi jawaban responden terletak pada item kesigapan PA (Penasehat Akademik) dalam melayani mahasiswa (X2.4) dengan rata-rata 3,32. Hal ini menunjukkan bahwa dosen PA (Penasehat Akademik) selalu siap dan bersedia membantu mahasiswanya dalam menyelesaikan masalah akademik mahasiswa. Sedangkan distribusi rata-rata terendah jawaban responden terletak pada item kesiapan dan kesigapan pegawai/ staf dalam melayani, menangani, dan menyelesaikan permintaan mahasiswa (X2.1) dengan rata-rata 2,28. Hal ini menunjukkan bahwa masih sangat kurangnya kesiapan dan kesediaan pegawai/ staf Fakultas Ilmu Komputer dalam membantu menyelesaikan pemasalahan yang dihadapi mahasiswa Fakultas Ilmu Komputer.

Tabel 9 Distribusi Frekuensi Item Variabel Kepastian (Assurance)

\begin{tabular}{|c|c|c|c|c|c|c|c|c|c|c|c|}
\hline \multirow[t]{2}{*}{ Variabel } & \multicolumn{2}{|c|}{$\begin{array}{l}1 \\
\text { STB }\end{array}$} & \multicolumn{2}{|l|}{$\begin{array}{l}2 \\
\text { TB }\end{array}$} & \multicolumn{2}{|c|}{$\begin{array}{l}3 \\
\text { CB }\end{array}$} & \multicolumn{2}{|l|}{$\begin{array}{l}4 \\
\text { B }\end{array}$} & \multicolumn{2}{|c|}{$\begin{array}{l}5 \\
\text { SB }\end{array}$} & \multirow{2}{*}{$\begin{array}{l}\text { Statistik } \\
\text { Mean }\end{array}$} \\
\hline & f & $\%$ & $\mathbf{F}$ & $\%$ & $\mathbf{F}$ & $\%$ & $\mathbf{f}$ & $\%$ & f & $\%$ & \\
\hline X3.1 & 53 & 35,1 & 23 & 15,23 & 46 & 30,46 & 29 & 19,21 & - & - & 2,34 \\
\hline X3.2 & 9 & 5,96 & 28 & 18,54 & 81 & 53,64 & 33 & 21,85 & - & - & 2,91 \\
\hline $\mathrm{X} 3.3$ & 7 & 4,64 & 63 & 41,72 & 56 & 37,09 & 25 & 16,56 & - & - & 2,66 \\
\hline X3.4 & 13 & 8,61 & 32 & 21,19 & 87 & 57,62 & 19 & 12,58 & - & - & 2,74 \\
\hline $\mathrm{X} 3.5$ & 13 & 8,61 & 51 & 33,77 & 65 & 43,05 & 22 & 14,57 & - & - & 2,64 \\
\hline X3.6 & 10 & 6,62 & 20 & 13,25 & 53 & 35,1 & 68 & 45,03 & - & - & 3,19 \\
\hline X3.7 & 9 & 5,96 & 15 & 9,93 & 87 & 57,62 & 40 & 26,49 & - & - & 3,05 \\
\hline X3.8 & - & - & 16 & 10,6 & 93 & 61,59 & 42 & 27,81 & - & - & 3,17 \\
\hline
\end{tabular}

Dari delapan item pernyataan variabel kepastian (assurance), distribusi rata-rata tertinggi jawaban responden terletak pada item komitmen jadwal kuliah (jam masuk-keluar) dilaksanakan dengan baik dan normal (perkuliahan tidak dilakukan pada malam hari) (X3.6) dengan rata-rata 3,19. Hal ini menunjukkan bahwa komitmen jadwal perkuliahan dilaksanakan dengan baik dan waktunya normal. Sedangkan untuk distribusi rata-rata terendah jawaban responden terletak pada item keramahan dan kesopanan pegawai/ staf dalam memberikan pelayanan (X3.1) dengan rata-rata 2,34. Hal ini menunjukkan bahwa pegawai/ staf Fakultas Ilmu Komputer masih kurang dapat menciptakan suasana akrab, cair, dan friendly ketika memberikan pelayanan kepada mahasiswa Fakultas Ilmu Komputer Universitas Lancang Kuning.

Tabel 10 Distribusi Frekuensi Item Variabel Ketulusan (Empathy)

\begin{tabular}{|c|c|c|c|c|c|c|c|c|c|c|c|}
\hline \multirow[t]{2}{*}{ Variabel } & \multicolumn{2}{|c|}{$\begin{array}{l}1 \\
\text { STB }\end{array}$} & \multicolumn{2}{|c|}{$\begin{array}{l}2 \\
\text { TB }\end{array}$} & \multicolumn{2}{|c|}{$\begin{array}{l}3 \\
\mathrm{CB}\end{array}$} & \multicolumn{2}{|l|}{$\begin{array}{l}4 \\
\text { B }\end{array}$} & \multicolumn{2}{|c|}{$\begin{array}{l}5 \\
\text { SB }\end{array}$} & \multirow{2}{*}{$\begin{array}{l}\text { Statistik } \\
\text { Mean }\end{array}$} \\
\hline & f & $\%$ & f & $\%$ & $\mathbf{F}$ & $\%$ & f & $\%$ & $\mathbf{F}$ & $\%$ & \\
\hline $\mathrm{X} 4.1$ & - & - & 15 & 9,93 & 95 & 62,91 & 41 & 27,2 & - & - & 3,17 \\
\hline $\mathrm{X} 4.2$ & - & - & 13 & 8,61 & 83 & 54,97 & 55 & 36,42 & - & - & 3,28 \\
\hline
\end{tabular}




\begin{tabular}{|l|l|l|l|l|l|l|l|l|l|l|l|} 
X4.3 & - & - & 9 & 5,96 & 82 & 54,3 & 60 & 39,74 & - & - & 3,34 \\
\hline X4.4 & - & - & 5 & 3,31 & 41 & 27,15 & 85 & 56,29 & 20 & 13,25 & 3,79 \\
\hline X4.5 & - & - & 7 & 4,64 & 63 & 41,72 & 76 & 50,33 & 5 & 3,31 & 3,52 \\
\hline X4.6 & - & - & 72 & 47,68 & 45 & 29,8 & 34 & 22,52 & - & - & 2,75 \\
\hline X4.7 & - & - & 54 & 35,76 & 74 & 49 & 23 & 15,23 & - & - & 2,79 \\
\hline X4.8 & - & - & 81 & 53,64 & 49 & 32,45 & 21 & 13,91 & - & - & 2,6 \\
\hline
\end{tabular}

Dari delapan item pernyataan variabel ketulusan (empathy), distribusi rata-rata tertinggi jawaban responden terletak pada item dosen selalu mendorong agar mahasiswa selesai menempuh pendidikan tepat waktu $(+4$ tahun) (X4.4) dengan rata-rata 3,79. Hal ini menunjukkan bahwa dosen selalu memotivasi dan mendorong agar mahasiswa selesai menempuh pendidikan tepat waktu. Sedangkan distribusi rata-rata terendah jawaban responden terletak pada item kesabaran staf/ pegawai dalam melayani mahasiswa (X4.8) dengan rata-rata 2,60. Hal ini menunjukkan bahwa masih kurangnya kesabaran staf/ pegawai dalam melayani permintaan mahasiswa.

Tabel 11 Distribusi frekuensi Item variabel Bukti fisik (Tanginles)

\begin{tabular}{|c|c|c|c|c|c|c|c|c|c|c|c|}
\hline \multirow[t]{2}{*}{ Variabel } & \multicolumn{2}{|c|}{$\begin{array}{l}1 \\
\text { STB }\end{array}$} & \multicolumn{2}{|l|}{$\begin{array}{l}2 \\
\text { TB }\end{array}$} & \multicolumn{2}{|c|}{\begin{tabular}{|l|}
3 \\
$\mathrm{CB}$ \\
\end{tabular}} & \multicolumn{2}{|l|}{$\begin{array}{l}4 \\
\text { B }\end{array}$} & \multicolumn{2}{|c|}{\begin{tabular}{|l}
5 \\
SB \\
\end{tabular}} & \multirow{2}{*}{$\begin{array}{l}\text { Statistik } \\
\text { Mean }\end{array}$} \\
\hline & f & $\%$ & f & $\%$ & $\mathbf{F}$ & $\%$ & f & $\%$ & f & $\%$ & \\
\hline X5.1 & - & - & 71 & 47,02 & 6 & 40,4 & 1 & 12,58 & - & - & 2,66 \\
\hline $\mathrm{X} 5.2$ & - & - & 27 & 17,88 & 9 & 61,5 & 3 & 20,53 & - & - & 3,03 \\
\hline $\mathrm{X} 5.3$ & 10 & 6,6 & 45 & 29,8 & 8 & 52,9 & 1 & 10,6 & - & - & 2,68 \\
\hline $\mathrm{X} 5.4$ & - & - & 35 & 23,18 & 9 & 60,2 & 2 & 16,56 & - & - & 2,93 \\
\hline $\mathrm{X} 5.5$ & 42 & 27 & 69 & 45,7 & 4 & 26,4 & - & - & - & - & 1,99 \\
\hline $\mathrm{X} 5.6$ & 88 & 58 & 41 & 27,15 & 2 & 14,5 & - & - & - & - & 1,56 \\
\hline $\mathrm{X} 5.7$ & 24 & 15 & 83 & 54,97 & 4 & 29,1 & - & - & - & - & 2,13 \\
\hline $\mathrm{X} 5.8$ & - & - & 57 & 37,75 & 7 & 48,3 & 2 & 13,91 & - & - & 2,76 \\
\hline X5.9 & - & - & - & - & \begin{tabular}{|l}
6 \\
0 \\
\end{tabular} & $\begin{array}{l}39,7 \\
4\end{array}$ & \begin{tabular}{|l}
8 \\
3 \\
\end{tabular} & 54,97 & 8 & 5,3 & 3,66 \\
\hline
\end{tabular}

Dari sembilan item pernyataan variabel bukti fisik (tangibles), distribusi rata-rata tertinggi jawaban responden terletak pada item penampilan dosen dan pegawai rapi dan meyakinkan (X5.9) dengan rata-rata 3,66. Hal ini menunjukkan bahwa penampilan dosen dan pegawai benar-benar rapi, sopan, dan meyakinkan mahasiswa Fakultas Ilmu Komputer. Sedangkan distribusi rata-rata terendah jawaban responden terletak pada item ketersediaan fasilitas olahraga (X5.6) dengan rata-rata 1,56. Hal ini menunjukkan bahwa mahasiswa merasa ketersediaan fasilitas olahraga fakultas masih sangat kurang lengkap. 
Tabel 12 Distribusi Frekuensi Item Kepuasan Mahasiswa

\begin{tabular}{|c|c|c|c|c|c|c|c|c|c|c|c|}
\hline \multirow[t]{2}{*}{ Variabel } & \multicolumn{2}{|c|}{$\begin{array}{l}1 \\
\text { STP } \\
\end{array}$} & \multicolumn{2}{|c|}{$\begin{array}{l}2 \\
\text { TP }\end{array}$} & \multicolumn{2}{|c|}{$\begin{array}{l}3 \\
\mathrm{CP}\end{array}$} & \multicolumn{2}{|c|}{\begin{tabular}{|l}
4 \\
$P$
\end{tabular}} & \multicolumn{2}{|c|}{\begin{tabular}{|l}
5 \\
SP
\end{tabular}} & \multirow{2}{*}{$\begin{array}{l}\text { Statistik } \\
\text { Mean } \\
\end{array}$} \\
\hline & f & $\%$ & f & $\%$ & $\mathbf{F}$ & $\%$ & f & $\%$ & f & $\%$ & \\
\hline $\bar{Y}$ & 16 & 10,6 & 51 & 33,77 & 76 & 50,33 & 8 & 5,3 & - & - & 2,5 \\
\hline
\end{tabular}

Distribusi frekuensi rata-rata jawaban responden terletak pada skala 3 kategori Cukup Puas (CP) dengan rata-rata 2,50. Hal ini menunjukkan bahwa masih rendahnya kepuasan mahasiswa Fakultas Ilmu Komputer Universitas Lancang Kuning terhadap kualitas pelayanan Fakultas, sehingga hal ini perlu dijadikan evaluasi bagi perbaikan kualitas pelayanan Fakultas Ilmu Komputer Universitas Lancang Kuning kedepan yang lebih baik.

\section{Kesimpulan}

Dari Pembahasan masalah yang telah diuraikan dapat disimpulkan:

1. Keandalan (reliability) (X1) berpengaruh signifikan terhadap tingkat kepuasan mahasiswa komputer Fakultas Ilmu Komputer Universitas Lancang Kuning (Y)

2. Daya tanggap (responsiveness) (X2) berpengaruh signifikan terhadap tingkat kepuasan mahasiswa komputer Fakultas Ilmu Komputer Universitas Lancang Kuning(Y)

3. Kepastian (assurance) (X3) berpengaruh signifikan terhadap tingkat kepuasan mahasiswa komputer Fakultas Ilmu Komputer Universitas Lancang Kuning(Y)

4. Ketulusan (empathy) (X4) tidak berpengaruh signifikan terhadap tingkat kepuasan mahasiswa komputer Fakultas Ilmu Komputer Universitas Lancang Kuning(Y)

5. Bukti fisik (tangibles) (X4) berpengaruh signifikan terhadap tingkat kepuasan mahasiswa komputer Fakultas Ilmu Komputer Universitas Lancang Kuning(Y).

6. Kualitas pelayanan (X) yang terdiri dari keandalan (reliability) (X1), daya tanggap (responsiveness) (X2), kepastian (assurance) (X3), ketulusan (empathy) (X4), dan bukti fisik (tangibles) (X5) secara simultan berpengaruh signifikan terhadap tingkat kepuasan mahasiswa komputer Fakultas Ilmu Komputer Universitas Lancang Kuning (Y).

Saran kedepannya Bagi Unsur Pelaksana Administrasi (Staf/Pegawai):

1. Hendaknya lebih sigap dan tanggap dalam melayani permintaan mahasiswa, jangan terlalu santai danmenunda-nunda.

2. Hendaknya bersikap ramah dalam melayani mahasiswa tanpa pandang bulu, tanpa memandang rupa atau status sosial mahasiswa

Bagi Unsur Pelaksana Akademis (Dosen Pengajar):

1. Hendaknya lebih komitmen dalam menentukan jadwal perkuliahan, sehingga tidak ada lagi perpindahan jadwal kuliah di kemudian hari.

2. Persentase kehadiran dan kedisiplinan dosen harus lebih ditingkatkan agar waktu belajar mahasiswa menjadi lebih efektif, dan mohon pemberitahuan secepatnya jika dosen berhalangan hadir, mengingat lokasi kampus yang sangat jauh dari kota.

Dari Aspek Fasilitas

Semua elemen kampus hendaknya lebih peka terhadap kebersihan, kerapian, dan kenyamanan fasilitas penunjang kelancaran proses perkuliahan, seperti ruang kuliah, perpustakaan dan lab.komputer, ebersihan toilet. Kelengkapan fasilitas perpustakaan sebaiknya lebih diperhatikan, terutama ketersediaan buku-buku referensi terbaru sebagai penunjang perkuliahan, dan perbaikan jaringan wifi. 


\section{Daftar pustaka}

[1] Arambewela, R. \& Hall, J. (2009). An empirical model of international student satisfaction. Asia Pacific Journal of Marketing and Logistics, 21(4)

[2] Jasfar, F. (2005). Manajemen Jasa: Pendekatan Terpadu. Bogor: Ghalia Indonesia.

[3] Lupiyoadi, Rambat. (2001). Edisi Pertama. Manajemen Pemasaran Jasa: Teori dan Praktik. Jakarta: Salemba Empat.

[4] Nasution. Metode Research : Peneltian Ilmiah. Jakarta: Bumi Aksara, 2007.

[5] Rinala, Yudana, \& Natajaya. (2013). Pengaruh Kualitas Pelayanan Akademik terhadap Kepuasan dan LoyalitasMahasiswa pada Sekolah Tinggi Pariwisata Nusa Dua Bali. $e$ journal, 2013, 4. 112.

[6] Sularni, D. (2013). Pengaruh Kualitas Pelayanan terhadap Kepuasan Mahasiswa (Studi pada Perpustakaan Fakultas Keguruan dan Ilmu Pendidikan Universitas Sebelas Maret Surakarta Angkatan Tahun 20102012).

[7] Tampubolon. (2001). Perguruan Tinggi Bermutu Paradigma Baru dan Manajemen Pendidikan Tinggi Menghadapi Tantangan Abad ke 21. Jakarta: PT Gramedia Pustaka Utama.

[8] Tjiptono, F., Chandra, G., \& Adriana, D. (2008). Pemasaran Strategik. Edisi 2. Yogyakarta: Andi Offset.

[9] Van FC LL, Lisnawita L. Analisis Kepuasan Pelanggan Terhadap Pelayanan Purnajual CV. Family Menggunakan Metode Fuzzy-Logic. INOVTEK-Seri Informatika. 2017 Jun 15;2(1):64-7.

[10] Yamit, Z, (2005). Manajemen Kualitas: Produk Dan Jasa. Yogyakarta: Ekonisia.

[11] Zaeni, A. (2007). Pengaruh Kualitas Pelayanan (Service Quality) terhadap Kepuasan Mahasiswa Fakultas Ekonomi Universitas Islam Negeri (UIN) Malang. Diperoleh 14 Januari 2014 